\title{
Risk Factors for Variant Creutzfeldt-Jakob Disease: A Case-Control Study
}

\author{
Hester J. T. Ward, FFPH, ${ }^{1}$ Dawn Everington, MSc, ${ }^{1}$ Simon N. Cousens, MA, ${ }^{2}$ Blaire Smith-Bathgate, RGN, ${ }^{1}$ \\ Margaret Leitch, RMN, ${ }^{1}$ Sarah Cooper, MRCP, ${ }^{1}$ Craig Heath, MRCP, ${ }^{1}$ Richard S. G. Knight, FRCPE, ${ }^{1}$ \\ Peter G. Smith, DSc, ${ }^{2}$ and Robert G. Will, FRCP ${ }^{1}$
}

\begin{abstract}
Objective: To investigate the potential risk factors for variant Creutzfeldt-Jakob disease (VCJD) in the United Kingdom. Methods: Definite and probable vCJD cases $(\mathrm{n}=136)$ were residing in Great Britain at disease onset, and were referred between May 1995 and November 2003. Control subjects $(n=922)$ were recruited between 2002 and 2003, from 100 randomly selected geographical clusters sampled to represent the geographical distribution of vCJD. Results: Reported frequent consumption of beef and beef products thought likely to contain mechanically recovered or head meat, or both, including burgers and meat pies, was associated with increased risk for vCJD, as was reported frequent chicken consumption. Surgical operations were generally similarly reported for cases and control subjects, with the exception of a small group of minor operations, possibly attributable to underreporting in control subjects. Cases and control subjects had similar reported occupational histories and exposure to animals. Interpretation: These findings are consistent with dietary exposure to contaminated beef products being the main route of infection of $\mathrm{vCJD}$, but recall bias cannot be excluded. There was no convincing evidence of increased risk through medical, surgical, or occupational exposure or exposure to animals.
\end{abstract}

Ann Neurol 2006;59:111-120

A new variant of Creutzfeldt-Jakob disease (vCJD) was first reported in the United Kingdom in 1996. ${ }^{1}$ The causal infectious agent is indistinguishable from that which causes bovine spongiform encephalopathy (BSE). ${ }^{2-5}$ Several million BSE-infected cattle probably entered the human food supply, and consumption of BSE-contaminated products is the most likely route by which humans were infected. ${ }^{6,7}$ However, direct evidence for dietary human infection is lacking. Probable human-to-human transmission of the vCJD agent via blood transfusion emphasizes that other transmission routes need to be considered. ${ }^{8,9}$ Beef mechanically recovered meat (MRM) and head meat might have been the major vehicles for human dietary exposure through inclusion in low-cost meat products, including burgers, sausages, and pies. ${ }^{10-15}$ MRM is obtained by using a high-pressure process to remove the residual raw meat from bones. Before the UK ban in 1995, vertebral columns were the major source of beef MRM, with consequent possible contamination with spinal cord and dorsal root ganglia. ${ }^{12,14}$ Head meat might have been contaminated with bovine brain. ${ }^{15}$

We report the results of a case-control study of
vCJD examining a wide range of potential risk factors, including dietary, medical, and occupational exposures.

\section{Subjects and Methods}

Since 1990, the UK National CJD Surveillance Unit (NCJDSU) has attempted to identify all cases of CJD in the United Kingdom, first describing vCJD in $1996 .{ }^{16}$ CJD cases are classified as "definite" or "probable" according to defined diagnostic criteria. ${ }^{17,18}$ In this study, we included all vCJD cases identified in Great Britain between May 1995 and November 2003.

Patients notified to the NCJDSU were, whenever possible, visited by a NCJDSU neurologist and a research nurse. The nature of vCJD precluded direct interviews of cases; therefore, after informed consent was provided, the research nurse interviewed a close relative, using a structured questionnaire that took about an hour to complete. Information was collected on a wide range of possible risk factors, including dietary, medical, surgical, occupational, and residential histories and exposure to animals and animal products. With respect to diet, relatives were asked to estimate how frequently, on average, the case had eaten each of 20 generic food items, for example, chicken or beef. Traditional foods such as haggis (typically containing sheep offal), black pud-
From the ${ }^{1}$ National Creutzfeldt-Jakob Disease Surveillance Unit, University of Edinburgh, Western General Hospital, Edinburgh; and ${ }^{2}$ Department of Infectious and Tropical Diseases, London School of Hygiene and Tropical Medicine, London, United Kingdom.

Received Jun 29, 2005, and in revised form Sep 8. Accepted for publication Sep 14, 2005.
Published online Nov 14, 2005, in Wiley InterScience (www.interscience.wiley.com). DOI: 10.1002/ana.20708

Address correspondence to Dr Ward, National CJD Surveillance Unit, University of Edinburgh, Western General Hospital, Crewe Road, Edinburgh, EH4 2XU, United Kingdom.

E-mail: h.ward@ed.ac.uk 
ding (containing pigs' blood), and faggots (containing minced pigs' liver and offal) were also included. One of eight responses was selected from a card: never, less than once per year, about once per year, several times per year, about once per month, about once per week, several times per week, and several times per day. We constructed a composite measure of $\mathrm{MRM} /$ head meat consumption using the combined frequencies of reported consumption of burgers, meat pies, and sausages. ${ }^{12-15}$

The initial method of selecting matched control subjects from the same general practice as each case proved complex and slow, with a poor response rate. ${ }^{19}$ Instead, we commissioned the National Centre for Social Research ${ }^{20}$ (NatCen) to recruit a random sample of individuals from the general population. The primary sampling units were postcode sectors, each containing, on average, about 2,700 residential addresses. The Scottish Isles were excluded from the sampling frame for logistical reasons together with one case of vCJD resident in the Scottish Isles at disease onset. A stratified random sample of 100 postcode sectors was drawn from the Postcode Address File. ${ }^{21}$ Within each standard region of Great Britain, postcode sectors were sorted by urban/rural status, and then within this by a measure of socioeconomic status (proportion of heads of household of non-manual occupational status). From a random starting point, a fixed number of postcode sectors were selected systematically from the ordered list within each region, with the number of sectors sampled fixed to ensure that the regional distribution of the control subjects was similar to that of the cases. Thus, $49 \%$ of the selected postcode sectors, and $47 \%$ of vCJD cases were in the "north" (Scotland, North, North West and Yorkshire and Humberside regions). ${ }^{22}$ Within each sampled postcode sector, 44 randomly selected addresses yielded a total sample of 4,400 addresses.

An age-weighted sampling procedure was used to ensure an adequate number of control subjects in those age groups with highest vCJD incidence (10-39 years), and to allow separate use of the control group for analysis with older sporadic CJD cases. A total of 4,400 addresses were selected, and to achieve the required age structure, eligibility for inclusion was taken to be those aged 10 years or older at $27 \%$ of addresses, those aged 10 to 39 years at $25 \%$ of addresses, and those aged 20 to 29 years at $48 \%$. Households with no individuals in the preselected age range were excluded.

NatCen-employed interviewers visited each sampled address up to four times to identify all eligible household residents, who had lived in Great Britain for at least 5 years between 1980 and 1996 and who had a living relative in the United Kingdom; only one individual was selected, at random, as a control subject in each household. Control subjects who consented were asked to nominate a relative residing in the United Kingdom for interview. For control subjects younger than 39 years, a parent was sought; failing that, a partner or sibling was requested. For control subjects older than 40 years, a partner was sought; failing that, a parent, sibling, or child was requested. Consenting relatives were interviewed by a NatCen interviewer using a questionnaire similar to that used for vCJD cases, but adapted for computer-assisted interviewing.
Because the control sample was to be suitable for separate comparison with sporadic CJD cases, the median age of control subjects (33 years) was greater than that of cases (26 years). We took full account of this age difference in the analyses. Proportions of control subjects exposed to putative risk factors were standardized directly to the birth cohort distribution of cases for presentation purposes. Logistic regression was used, adjusting for sex, birth cohort, north/south residency at onset for cases (at interview for control subjects), and consumption of certain food items (see footnote to Table 2). Magnitude of associations were assessed by odds ratios (ORs) with 95\% confidence intervals (95\% CIs) using a "robust" variance estimate, taking account of cluster sampling of control subjects. ${ }^{23-25}$ For the place of residence at onset for cases (at interview for controls), we identified an Index of Multiple Deprivation (IMD) score ${ }^{26}$ by linking the postcode to the databases of IMD for England and Wales (2000) and Scotland (2003). Cases and control subjects were assigned to quintiles according to their IMD score within England, Scotland, or Wales.

The study had $70 \%$ power to detect factors associated with a doubling of risk if their prevalence was between 10 and $90 \%$, and $80 \%$ power to detect factors associated with a 2.2-fold increase in risk.

The Lothian Multi-centre Research Ethics Committee approved this study.

\section{Results}

Between May 1995 and November 2003, 136 cases (100 definite, 36 probable) of vCJD were identified in Great Britain, with risk factor questionnaires completed for 133 (98\%); 132 cases (97 definite, 35 probable) were included in the analyses (1 Scottish Isles case was excluded). The blood transfusion-associated vCJD case $^{8}$ was identified after November 2003 and was not included. Of the 4,400 addresses selected by NatCen, 385 (9\%) were excluded because they were nonresidential and 2,148 because no residents met age or residency criteria. A control subject was recruited from $1,065(57 \%)$ of the remaining 1,867 eligible addresses. No control subject was recruited from 802 addresses. The selected control individual refused to participate in 561 addresses, the interviewer was unable to contact the selected control individual in 147 , and there were other reasons in 94, including failure to make contact with anyone at the address. Between 2002 and 2003, 922 relatives were interviewed (87\% of consenting control subjects; $49 \%$ of eligible addresses).

Median age at interview was 26 (range, 13-75) years for cases and 33 (range, 10-91) years for control subjects. Sixty female cases (45\%) and 478 female control subjects $(52 \%)$ were included in the study. Table 1 shows the distribution of cases and control subjects by year of birth. Ninety-two percent of cases and 90\% of control subjects were lifetime UK residents. Respondents for those born before 1970 were predominantly partners (63\% for cases and 60\% for control subjects), followed by parents for cases (29\%) and a mixture of 
Table 1. Year of Birth of Variant Creutzfeldt-Jakob Disease Cases and General Population Control Subjects

\begin{tabular}{lcc}
\hline $\begin{array}{l}\text { Year of } \\
\text { Birth }\end{array}$ & $\begin{array}{c}\text { vCJD Cases } \\
(\mathrm{n}=132) \\
(\%)\end{array}$ & $\begin{array}{c}\text { General Population } \\
\text { Control Subjects } \\
(\mathrm{n}=922)(\%)\end{array}$ \\
\hline$\leq 1929$ & $1(0.8)$ & $54(5.9)$ \\
$1930-1939$ & 0 & $73(7.9)$ \\
$1940-1949$ & $7(5.3)$ & $84(9.1)$ \\
$1950-1959$ & $9(6.8)$ & $81(8.8)$ \\
$1960-1969$ & $35(26.5)$ & $162(17.6)$ \\
$1970-1979$ & $55(41.7)$ & $229(24.8)$ \\
$1980-1989$ & $25(18.9)$ & $188(20.4)$ \\
$1990-1999$ & 0 & $51(5.5)$
\end{tabular}

vCJD $=$ variant Creutzfeldt-Jakob disease.

parents (14\%) and children (16\%) for control subjects. For those born since 1970, parents were the main respondents ( $85 \%$ cases, $77 \%$ control subjects), followed by partners (10\% cases, $16 \%$ control subjects).

\section{Diet}

Table 2 shows reported consumption of different food items by cases and control subjects. Cases were reported to have consumed beef, burgers, meat pies, and chicken more frequently than control subjects $(p \leq$ 0.03 ), and liver consumption was also higher among cases $(p=0.06)$. There was little evidence that consumption of sausages, faggots, haggis, pork, lamb, or venison was associated with risk for $\operatorname{vCJD}(p \geq 0.1)$. Frequent consumption of kidney, black pudding, and veal was less common in cases than control subjects. Cases were reported to have consumed products most likely to have contained MRM/head meat more often than control subjects. This pattern of associations appeared to be broadly similar in both the 1940 to 1969 and 1970 to 1989 birth cohorts (data not shown). Brain consumption was reported for 3 cases $(2.3 \%$; 1 porcine, 2 unknown) and 24 control subjects $(2.6 \%)$.

Six $(4.5 \%)$ cases and $65(8.1 \%)$ control subjects were reported to have been vegetarians for at least 1 year. For part of the likely greatest BSE exposure period (1980-1996), 5 cases (3.7\%) and 50 (6.7\%) control subjects $(p=0.2)$ were reported to be vegetarians (Table 3), with a mean of 6 years of vegetarianism for both cases (range, 2-10 years) and control subjects (range, 1-16 years). Three of the five cases were reported to have sometimes eaten fish or white meats when vegetarian. Five control subjects (two of whom were reported to have eaten no meat or fish), but no cases, were reported to be vegetarians for the whole period. There was no evidence that the histories of eating school meals, pet food, or chopping raw meat were different for cases and control subjects. Approximately the same proportions of cases and control subjects were re- ported to have ever had any dietary restrictions (see Table 3).

\section{Occupation}

There was no evidence that any of the occupations that we identified, a priori, as potential high-risk occupations for vCJD were associated with an increased risk for vCJD (Table 4). Thirteen cases $(10.0 \%)$ had worked on a cattle farm, as a butcher, in an abattoir, or in the meat preparation industry, some working in more than one category, compared with 58 (6.2\%) control subjects $(p=0.1)$. Two cases had lived all their lives on cattle farms, neither of which had ever reported BSE (J. Wilesmith, personal communication). A further three cases had worked on cattle farms for 1 year (year of onset), 6 years ( $0-5$ years before onset), and 12 years (1-13 years before onset). Three cases had worked as butchers for between 6 months and 4 years, either within 4 years of onset (one case) or greater than 15 years before onset. Two cases had worked in abattoirs for up to 1 year, one within 10 years of onset and the other 15 to 16 years before onset. Seven cases were reported to have worked in meat preparation, five within 5 to 10 years of onset (burger $[\mathrm{n}=1]$ and white pudding $[\mathrm{n}=1]$ preparation, meat packing $[n=4]$, cooked meat preparation $[n=1])$, and one of seven which was reported as only working with poultry. These histories were unexceptional when compared with those of the control subjects.

\section{Medical History}

Relatives were asked to report any surgical procedures that cases and control subjects had experienced, excluding those since clinical onset of vCJD (Table 5). Fifty-eight percent of cases and 59\% of control subjects were reported to have had a surgical operation since 1980. There was no evidence that surgery on specific organ systems was associated with increased risk for vCJD, but there was evidence of an association with "other operations" (defined in Table 5) $(p=0.01)$. Many of these were stitching of skin wounds ( $27 \%$ of cases and $11 \%$ of control subjects), removal of growths, cysts and moles ( $8 \%$ of cases and $4 \%$ of control subjects), and nose and throat operations ( $5 \%$ of cases and $2 \%$ of control subjects). When "other" operations were divided into stitching of skin wounds only and the remainder, only the remaining procedures were significantly more common among cases $(p=0.03)$.

The reported frequencies of other potential medical and related risk factors for cases and control subjects are shown in Table 6 , with no evidence that any, in particular blood transfusion, were more common among cases. 


\begin{tabular}{|c|c|c|c|c|c|}
\hline $\begin{array}{l}\text { Food Item Eaten } \\
\text { since } 1980\end{array}$ & $\begin{array}{l}\text { Frequency of } \\
\text { Reported } \\
\text { Consumption }\end{array}$ & $\begin{array}{c}\% \text { of vCJD Cases } \\
\left(\mathrm{n}=132^{\mathrm{a}}\right)\end{array}$ & $\begin{array}{c}\% \text { of General } \\
\text { Population Control } \\
\text { Subjects } \mathrm{b}^{\mathrm{b}} \\
\left(\mathrm{n}=922^{\mathrm{a}}\right)\end{array}$ & $\mathrm{OR}^{\mathrm{c}}(95 \% \mathrm{CI})$ & $\begin{array}{l}p \text { for } \\
\text { Trend }\end{array}$ \\
\hline \multirow[t]{3}{*}{ Beef } & $<1$ per week & 22.8 & 33.5 & 1.0 & \multirow[t]{3}{*}{0.03} \\
\hline & 1 per week & 35.9 & 45.4 & $1.0(0.6-1.8)$ & \\
\hline & $>1$ per week & 41.3 & 21.1 & $1.9(1.1-3.5)$ & \\
\hline \multirow{3}{*}{ Burgers } & $<1$ per week & 42.2 & 67.1 & 1.0 & \multirow[t]{3}{*}{$<0.0001$} \\
\hline & 1 per week & 24.7 & 26.3 & $1.4(0.8-2.4)$ & \\
\hline & $>1$ per week & 32.3 & 6.6 & $5.0(2.7-9.1)$ & \\
\hline \multirow[t]{3}{*}{ Sausages } & $<1$ per week & 38.6 & 47.1 & 1.0 & \multirow[t]{3}{*}{0.8} \\
\hline & 1 per week & 39.4 & 43.6 & $0.8(0.5-1.2)$ & \\
\hline & $>1$ per week & 22.0 & 9.3 & $1.0(0.5-2.1)$ & \\
\hline \multirow{3}{*}{ Meat pies } & $<1$ per week & 52.3 & 70.3 & 1.0 & \multirow[t]{3}{*}{0.009} \\
\hline & 1 per week & 31.4 & 23.9 & $1.5(0.9-2.5)$ & \\
\hline & $>1$ per week & 16.2 & 5.8 & $2.7(1.3-5.6)$ & \\
\hline \multirow{3}{*}{$\begin{array}{l}\text { MRM/head } \\
\text { meat }^{d}\end{array}$} & $\leq 3$ per month & 15.4 & 36.0 & 1.0 & \multirow[t]{3}{*}{$<0.0001$} \\
\hline & $\begin{array}{l}>3 \text { and }<8 \\
\text { per month }\end{array}$ & 17.6 & 24.0 & $1.7(0.9-3.2)$ & \\
\hline & $\geq 8$ per month & 66.2 & 40.0 & $3.3(1.8-5.9)$ & \\
\hline \multirow{3}{*}{ Faggots $^{\mathrm{e}}$} & Never & 64.7 & 78.8 & 1.0 & \multirow[t]{3}{*}{0.2} \\
\hline & $\leq 1$ per year & 18.0 & 10.6 & $2.0(1.1-3.7)$ & \\
\hline & $>1$ per year & 17.2 & 10.6 & $1.3(0.7-2.7)$ & \\
\hline \multirow[t]{3}{*}{ Haggis $^{\mathrm{f}}$} & Never & 75.8 & 73.6 & 1.0 & \multirow[t]{3}{*}{0.1} \\
\hline & $<1$ per year & 15.2 & 10.2 & $1.5(0.8-2.8)$ & \\
\hline & $\geq 1$ per year & 9.1 & 16.2 & $0.4(0.2-1.0)$ & \\
\hline \multirow{3}{*}{ Black pudding ${ }^{g}$} & Never & 65.6 & 62.2 & 1.0 & \multirow{3}{*}{0.02} \\
\hline & $\leq 1$ per year & 16.1 & 11.0 & $1.2(0.7-2.3)$ & \\
\hline & $>1$ per year & 18.3 & 26.8 & $0.5(0.3-0.8)$ & \\
\hline \multirow[t]{3}{*}{ Liver } & Never & 38.6 & 49.6 & 1.0 & \multirow[t]{3}{*}{0.06} \\
\hline & $\leq 1$ per year & 20.5 & 20.7 & $1.4(0.8-2.6)$ & \\
\hline & $>1$ per year & 40.9 & 29.7 & $1.7(1.0-2.8)$ & \\
\hline \multirow[t]{3}{*}{ Kidney } & Never & 69.7 & 67.2 & 1.0 & \multirow[t]{3}{*}{0.005} \\
\hline & $\leq 1$ per year & 18.2 & 15.3 & $0.9(0.5-1.6)$ & \\
\hline & $>1$ per year & 12.1 & 17.5 & $0.3(0.2-0.7)$ & \\
\hline \multirow[t]{3}{*}{ Chicken } & $<1$ per week & 4.5 & 15.6 & 1.0 & \multirow[t]{3}{*}{0.01} \\
\hline & 1 per week & 42.4 & 45.0 & $3.3(1.3-8.4)$ & \\
\hline & $>1$ per week & 53.0 & 39.4 & $3.5(1.4-8.9)$ & \\
\hline \multirow[t]{3}{*}{ Pork } & $<1$ per week & 22.0 & 31.8 & 1.0 & 0.2 \\
\hline & 1 per week & 37.1 & 41.9 & $1.3(0.7-2.3)$ & \\
\hline & $>1$ per week & 40.9 & 26.3 & $1.5(0.8-2.8)$ & \\
\hline Lamb & $<1$ per month & 44.7 & 43.9 & 1.0 & 0.1 \\
\hline & 1 per month & 25.0 & 27.8 & $0.8(0.5-1.4)$ & \\
\hline & $\geq 1$ per week & 30.3 & 28.3 & $0.7(0.4-1.1)$ & \\
\hline Venison & Never & 81.1 & 80.1 & 1.0 & 0.2 \\
\hline & $<1$ per year & 14.4 & 11.6 & $0.9(0.4-1.7)$ & \\
\hline & $\geq 1$ per year & 4.5 & 8.3 & $0.6(0.2-1.3)$ & \\
\hline Veal & Never & 87.1 & 80.6 & 1.0 & 0.06 \\
\hline & $<1$ per year & 6.8 & 11.0 & $0.5(0.2-1.1)$ & \\
\hline & $\geq 1$ per year & 6.1 & 8.4 & $0.5(0.2-1.2)$ & \\
\hline
\end{tabular}

${ }^{a}$ Number of responses for cases varied between 123 and 132; responses for control subjects varied between 880 and 922 .

${ }^{\mathrm{b}}$ Proportions standardized to the birth cohort distribution of cases.

${ }^{\mathrm{c}}$ Adjusted for frequency of consumption of beef, sausages, meat pies, and burgers; sex; north/south residence; and birth cohort, except when adjusting the OR for specific items included in the list of confounding factors, that specific item was excluded. The ORs associated with $\mathrm{MRM} /$ head meat ${ }^{\mathrm{d}}$ consumption were adjusted for frequency of consumption of beef, sex, north/south residence, and birth cohort.

${ }^{\mathrm{d}} \mathrm{MRM} /$ head meat: grouped measure that includes those items thought likely to contain MRM and/or head meat, that is, burgers, meat pies, and sausages. ${ }^{12-15}$

'Faggots traditionally contained minced pigs' liver and offal. Beef MRM was likely to have been included in its early production. ${ }^{13}$

fHaggis traditionally contained sheep offal (lung, liver, heart, stomach).

'Black pudding traditionally contained pigs' blood.

vCJD = variant Creutzfeldt-Jakob disease; $\mathrm{OR}=$ odds ratio; $\mathrm{CI}=$ confidence interval; $\mathrm{MRM}=$ mechanically recovered meat. 


\begin{tabular}{lccc}
\hline Dietary Risk Factor & $\begin{array}{c}\text { \% of vCJD Cases } \\
\left(\mathrm{n}=132^{\mathrm{a}}\right)\end{array}$ & $\begin{array}{c}\text { \% of General Population } \\
\text { Control Subjects } \\
\left(\mathrm{n}=922^{\mathrm{c}}\right)\end{array}$ & OR $^{\mathrm{d}}(95 \% \mathrm{CI})$ \\
\hline Ever been vegetarian for $\geq 1 \mathrm{yr}$ & 4.5 & 8.1 & $0.6(0.2-1.3)$ \\
School dinners: ever & 76.1 & 86.4 & $0.6(0.3-1.1)$ \\
Pet food: ever eaten since 1980 & 3.9 & 5.0 & $0.7(0.2-2.1)$ \\
Chopped raw meat: ever & 55.7 & 58.9 & $0.9(0.6-1.4)$ \\
Dietary restrictions: ever & 14.4 & 12.3 & $1.2(0.7-2.1)$ \\
\hline
\end{tabular}

${ }^{\mathrm{a}}$ Number of responses for cases varied between 101 and 132, except for school dinners ever eaten $(\mathrm{n}=80)$.

${ }^{\mathrm{b}}$ Proportions standardized to the birth cohort distribution of cases.

${ }^{\mathrm{C}}$ Number of responses for control subjects varied between 909 and 922, except for school dinners ever eaten $(\mathrm{n}=799)$.

${ }^{\mathrm{d}}$ Adjusted for sex, north/south residence, and birth cohort.

$\mathrm{vCJD}=$ variant Creutzfeldt - Jakob disease; $\mathrm{OR}=$ odds ratio; $\mathrm{CI}=$ confidence interval.

\section{Contact with Animals, Pesticides, and Fertilizers}

There was no evidence that the following were more common among cases: contact or living with any of the animal species listed in Table 7; living/staying on a farm since 1980; participation in cattle warble fly treatment (one case), sheep dipping (three cases), or crop spraying (one case); using bone meal, hoof and horn, dried blood, or manure in gardening. Cases were no more likely than control subjects to have dissected animal eyes at school (29\% of cases, $26 \%$ of control subjects; OR, 1.1; 95\% CI, 0.7-1.9).

\section{Socioeconomic Status and Years of Education}

The distribution of cases and control subjects was similar across IMD quintiles $(p=0.3)$. Cases and control subjects older than 21 years had similar durations of education (median, 12 years for both cases [range, $0-21$ years] and control subjects [range, $1-25$ years]; $p$ $=0.6$ ).

\section{Discussion}

We observed differences between the reported dietary histories of cases and control subjects, consistent with the hypothesis that dietary exposure has been the major route of infection through which humans have been infected with the BSE agent. We found no socioeconomic or educational differences between cases and control subjects to explain these findings. Our findings also suggest that it is unlikely that a high proportion of vCJD cases included in this study were infected through occupational or medical/surgical exposure, in particular through blood transfusion.

The major sources of BSE infectivity in UK human food may have been those products containing beef MRM or head meat, or both; MRM reportedly used in the production of burgers, sausages, and other meat products, and head meat reportedly mainly used in burgers. ${ }^{12-15}$ Another study reported that mince, especially frozen mince, contained a higher proportion of

Table 4. Reported Lifetime Occupational Histories

\begin{tabular}{|c|c|c|c|}
\hline \multirow[b]{2}{*}{ Occupation } & \multicolumn{2}{|c|}{ Ever Employed in Occupational Category } & \multirow[b]{2}{*}{$\mathrm{OR}^{\mathrm{b}}(95 \% \mathrm{CI})$} \\
\hline & $\begin{array}{c}\% \text { of vCJD Cases } \\
(\mathrm{n}=130)\end{array}$ & $\begin{array}{l}\% \text { of General Population } \\
\text { Control Subjects } \\
(\mathrm{n}=920)\end{array}$ & \\
\hline Animal farming/veterinary medicine & 6.2 & 4.4 & $1.4(0.6-3.2)$ \\
\hline Meat industry & 7.7 & 5.2 & $1.5(0.7-3.1)$ \\
\hline Catering industry, likely contact with raw meat & $7.8^{\mathrm{c}}$ & $5.5^{\mathrm{d}}$ & $1.5(0.7-3.1)$ \\
\hline Medical/paramedical/nursing/dentistry & 5.4 & 11.1 & $0.5(0.2-1.1)$ \\
\hline Laboratories: animal, pharmaceutical, and other & 0.8 & 3.5 & $0.2(0.0-1.8)$ \\
\hline Other occupations involving animal products & 4.6 & 2.7 & $1.8(0.7-4.6)$ \\
\hline Occupations involving contact with animalse & 16.1 & 10.8 & $1.6(0.9-2.7)$ \\
\hline
\end{tabular}

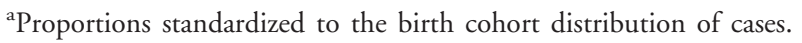

${ }^{\mathrm{b}}$ Adjusted for sex, north/south residence, and birth cohort.

${ }_{n}{ }_{n}=127$ and ${ }^{d} n=886$ : there were less cases and control subjects in this category because it was not possible to determine whether there had been likely contact with raw meat from all case and control occupational histories.

${ }^{\mathrm{e}} \mathrm{A}$ combined measure including those ever employed in animal farming, veterinary medicine, meat industry, animal laboratories, and other occupations involving animal products.

vCJD = variant Creutzfeldt-Jakob disease; $\mathrm{OR}=$ odds ratio; $\mathrm{CI}=$ confidence interval. 


\begin{tabular}{lccc}
\hline Surgical History since 1980 & $\begin{array}{c}\text { \% of vCJD Cases } \\
\left(\mathrm{n}=132^{\mathrm{a}}\right)\end{array}$ & $\begin{array}{c}\text { \%of General Population } \\
\text { Control Subjects } \\
\left(\mathrm{n}=922^{\mathrm{b}}\right)\end{array}$ & OR $^{\mathrm{d}}(95 \% \mathrm{CI})$ \\
\hline Any operation & 57.6 & 58.8 & $1.0(0.6-1.4)$ \\
Neurological & 0.8 & 2.4 & $0.4(0.0-3.0)$ \\
Eye & 3.0 & 2.8 & $1.0(0.3-3.1)$ \\
Ear & 3.0 & 4.5 & $0.7(0.2-1.9)$ \\
Orthopedic & 10.0 & 11.5 & $0.8(0.4-1.5)$ \\
Abdominal & 9.1 & 10.4 & $0.9(0.5-1.7)$ \\
Gynecological & 31.0 & 32.3 & $1.0(0.5-1.8)$ \\
Tonsillectomy & 3.0 & 7.2 & $0.4(0.1-1.2)$ \\
Appendicectomy & 3.0 & 3.0 & $1.0(0.3-2.9)$ \\
Any other operation: & 35.6 & 24.1 & $1.7(1.1-2.5)$ \\
$\quad$ Stitches to skin wounds only & 12.9 & 9.4 & $1.4(0.8-2.4)$ \\
All others & 22.7 & 14.5 & $1.7(1.1-2.6)$ \\
\hline
\end{tabular}

Data exclude those surgical procedures relating to vCJD illness for cases.

${ }^{a}$ Number of responses for cases varied between 131 and 132, except gynecological surgery ( $\mathrm{n}=60$; female cases only).

broportions standardized to the birth cohort distribution of cases.

${ }^{\mathrm{c}}$ Number of responses for control subjects varied between 903 and 922, except gynecological surgery $(\mathrm{n}=470$; female subjects only).

${ }^{\mathrm{d}}$ Adjusted for sex, north/south residence, and birth cohort.

vCJD = variant Creutzfeldt-Jakob disease; $\mathrm{OR}=$ odds ratio; $\mathrm{CI}=$ confidence interval.

MRM than other products, and that offal and MRM (for a limited period) were included in faggots. ${ }^{13} \mathrm{We}$ did not ask a specific question about mince.

There was evidence from this study of increased risk for vCJD associated with the frequency of consuming beef and some items likely to have contained MRM/ head meat, namely, burgers and meat pies (see Table 2). However, reported consumption of chicken was also more frequent in cases than control subjects. Our ability to control confounding is likely to have been hampered by measurement error in relatives' recall of cases' and control subjects' food consumption patterns 10 years or more previously. Although there is some circumstantial evidence that some chicken and pork products contained "beef" MRM, we have no explanation for the apparent association with chicken con-

Table 6. Reported Lifetime Histories of Other Medical and Related Risk Factors

\begin{tabular}{|c|c|c|c|}
\hline Medical Risk Factor & $\begin{array}{l}\% \text { of vCJD Cases } \\
\left(\mathrm{n}=132^{\mathrm{a}}\right)\end{array}$ & $\begin{array}{l}\% \text { of General Population } \\
\text { Control Subjects } \\
\left(\mathrm{n}=922^{\mathrm{c}}\right)\end{array}$ & $\mathrm{OR}^{\mathrm{d}}(95 \% \mathrm{CI})$ \\
\hline Blood transfusion & 6.8 & 6.1 & $1.2(0.6-2.7)$ \\
\hline Invasive dental treatment (since 1980) & 49.4 & 51.9 & $0.9(0.6-1.4)$ \\
\hline Contact lenses & 20.0 & 15.5 & $1.6(0.8-3.0)$ \\
\hline Admission to hospital & 38.6 & 34.0 & $1.3(0.9-1.9)$ \\
\hline Attendance at family doctor/hospital outpatient & 32.6 & 27.6 & $1.3(0.8-1.9)$ \\
\hline Seen by a psychiatrist & 9.1 & 8.5 & $1.2(0.6-2.3)$ \\
\hline Regular medication & 52.3 & 47.3 & $1.3(0.9-2.0)$ \\
\hline Relative diagnosed with dementia & 18.9 & 19.6 & $0.9(0.6-1.5)$ \\
\hline Allergy testing using needles & 2.8 & 4.8 & $0.6(0.2-1.9)$ \\
\hline Course of injections & 7.8 & 8.5 & $0.9(0.4-2.0)$ \\
\hline Lumbar puncture & 2.1 & 5.2 & $0.4(0.1-1.8)$ \\
\hline Acupuncture & 4.5 & 4.0 & $1.1(0.5-2.6)$ \\
\hline Tattoo & 15.9 & 20.8 & $0.7(0.4-1.2)$ \\
\hline Body piercing & 61.2 & 65.9 & $1.1(0.7-2.0)$ \\
\hline Intravenous recreational drugs & 1.1 & 0.7 & $1.1(0.1-10.3)$ \\
\hline
\end{tabular}

${ }^{a}$ Number of responses for cases varied between 100 and 132 .

${ }^{b}$ Proportions standardized to the birth cohort distribution of cases.

${ }^{c}$ Number of responses for control subjects varied between 920 and 922 .

${ }^{\mathrm{d}}$ Adjusted for sex, north/south residence, and birth cohort.

$\mathrm{vCJD}=$ variant Creutzfeldt-Jakob disease; $\mathrm{OR}=$ odds ratio; $\mathrm{CI}=$ confidence interval. 


\begin{tabular}{lccc}
\hline Exposure & $\begin{array}{c}\text { \% of vCJD Cases } \\
\left(\mathrm{n}=132^{\mathrm{a}}\right)\end{array}$ & $\begin{array}{c}\text { \% of General Population } \\
\text { Control Subjects } \\
\left(\mathrm{n}=922^{\mathrm{b}}\right)\end{array}$ & OR $^{\mathrm{d}}(95 \% \mathrm{CI})$ \\
\hline Cattle & 7.6 & 5.5 & $1.4(0.7-2.8)$ \\
Sheep & 5.4 & 4.0 & $1.3(0.5-2.9)$ \\
Goats & 2.1 & 1.3 & $1.4(0.3-6.1)$ \\
Pigs & 3.1 & 4.6 & $1.1(0.4-3.3)$ \\
Chickens & 7.0 & 0.3 & $1.3(0.5-2.9)$ \\
Mink & 0.8 & 52.0 & $2.0(0.2-18.9)$ \\
Cats & 59.2 & 68.8 & $1.3(0.9-1.9)$ \\
Dogs & 67.3 & 5.9 & $1.0(0.6-1.4)$ \\
Ferrets & 5.5 & 14.9 & $0.9(0.4-2.0)$ \\
Lived/stayed on farm & 17.4 & 0.3 & $1.2(0.7-2.0)$ \\
$\quad$ since 1980 & 1.1 & 1.7 & $3.0(0.3-29.0)$ \\
Warble fly treatment & 3.0 & 1.0 & $1.5(0.4-5.7)$ \\
Sheep dipping & 1.1 & 1.4 & $0.9(0.1-8.0)$ \\
Crop spraying & 9.1 & 2.9 & $0.6(0.3-1.1)$ \\
Bone meal & 2.3 & 4.5 & $0.8(0.2-2.6)$ \\
Hoof and horn & 2.3 & 16.9 & $0.4(0.1-1.5)$ \\
Dried blood & 10.6 & & $0.5(0.3-1.0)$ \\
Manure & & & \\
\hline
\end{tabular}

${ }^{a}$ Number of responses for cases varied between 103 and 132 .

bProportions standardized to the birth cohort distribution of cases.

${ }^{\mathrm{c}}$ Number of responses for control subjects varied between 825 and 922 .

${ }^{\mathrm{d}}$ Adjusted for sex, north/south residence, and birth cohort.

$\mathrm{vCJD}=$ variant Creutzfeldt-Jakob disease; $\mathrm{OR}=$ odds ratio; $\mathrm{CI}=$ confidence interval.

sumption (see Table 2). This may be due to biased recall or may be chance finding. An excess of male cases has been predicted by consumption studies. ${ }^{12,14,15}$ There is a small, non-statistically significant excess of male cases in this case series (OR, 1.3; 95\% $\mathrm{CI}, 0.9-1.8$ ), which is reduced (OR, 0.9; $95 \% \mathrm{CI}$, $0.6-1.4)$ when dietary items are adjusted for, an observation compatible with the excess of male cases being explained by sex differences in diet.

The only medical/surgical factor associated with increased risk for vCJD was a history of "other surgery." This surgery was usually relatively minor, such as skin stitches, and if case relatives were more likely to recall minor surgery than control subjects, then recall bias could explain this observation. A comparison of relatives' responses with those from control subjects themselves (16\% random sample of control subjects) showed that relatives underreported "other" operations compared with control subjects themselves: $39 \%$ of control subjects reported an "other" operation compared with $29 \%$ of their relatives ( $p=0.01$ ), and $13 \%$ of control subjects reported stitches compared with $10 \%$ of relatives $(p=0.3)$. We could not obtain data directly from vCJD cases. There was no difference in the lifetime number of operations reported for cases and control subjects $(p=0.9 ; 18.2 \%$ of cases and $17.4 \%$ of control subjects were reported to have undergone three or more operations).
Restricting the analysis to surgery after 1985 or 1990 (data not shown) did not indicate any statistically significant associations. Recall by cases' relatives of minor operations further in the past may explain the association with "other" operations (after 1980). If secondary transmission through surgery results in a relatively short incubation period (5-10 years), surgery since 1985 is more relevant than earlier. Thus, our data do not suggest that surgery is an important cause of $\mathrm{vCJD}$ in this case series. There was weak evidence of an association between tonsillectomy since 1980 and reduced risk for vCJD, which was strengthened when lifetime history of tonsillectomy was examined (OR, 0.5; 95\% CI, 0.3-1.0; $p=0.05$ ). A possible explanation is that an intact lymphoreticular system may be important in the pathogenesis of CJD. ${ }^{27}$

This study had a number of constraints that limit the strength of conclusions drawn from it. For logistical reasons, we were unable to recruit a satisfactory control group drawn from general practice lists, ${ }^{19}$ using instead a general population control group. Case relatives were interviewed by one of two NCJDSU research nurses (B.S.-B., M.L.) using paper questionnaires. Control relatives were interviewed by 1 of 114 NatCen interviewers using a computerized questionnaire. NatCen interviewers were trained specifically for this study, but they were not medical or vCJD 
Table 8. Average Reported Consumption since 1980 of Selected Food Items by Variant Creutzfeldt-Jakob Disease Cases and Suspect Cases

\begin{tabular}{|c|c|c|c|c|}
\hline $\begin{array}{l}\text { Food Item Eaten } \\
\text { since } 1980\end{array}$ & $\begin{array}{l}\text { Frequency of Reported } \\
\text { Consumption }\end{array}$ & $\begin{array}{c}\% \text { of vCJD Cases } \\
\left(\mathrm{n}=132^{\mathrm{a}}\right)\end{array}$ & $\begin{array}{c}\% \text { of Suspect Cases } \\
\left(\mathrm{n}=33^{\mathrm{b}}\right)\end{array}$ & $\mathrm{OR}^{\mathrm{d}}(95 \% \mathrm{CI})$ \\
\hline \multirow[t]{3}{*}{ Beef } & $<1$ per week & 22.8 & 22.9 & 1.0 \\
\hline & 1 per week & 35.9 & 38.4 & $1.0(0.3-2.9)$ \\
\hline & $>1$ per week & 41.3 & 38.0 & $1.3(0.5-3.9)$ \\
\hline \multirow[t]{3}{*}{ Burgers } & $<1$ per week & 42.2 & 49.7 & 1.0 \\
\hline & 1 per week & 24.7 & 22.4 & $1.0(0.3-2.9)$ \\
\hline & $>1$ per week & 32.3 & 27.2 & $1.0(0.4-2.8)$ \\
\hline \multirow[t]{3}{*}{ Sausages } & $<1$ per week & 38.6 & 30.5 & 1.0 \\
\hline & 1 per week & 39.4 & 47.7 & $0.6(0.2-1.6)$ \\
\hline & $>1$ per week & 22.0 & 21.0 & $0.8(0.3-2.5)$ \\
\hline \multirow{3}{*}{ Meat pies } & $<1$ per week & 52.3 & 63.8 & 1.0 \\
\hline & 1 per week & 31.4 & 24.3 & $1.2(0.4-3.2)$ \\
\hline & $>1$ per week & 16.2 & 11.1 & $1.2(0.3-4.2)$ \\
\hline \multirow{3}{*}{$\underset{\text { meat }^{\mathrm{e}}}{\mathrm{MRM} / \mathrm{head}}$} & $\leq 3$ per month & 15.4 & 20.7 & 1.0 \\
\hline & $\begin{array}{l}>3 \text { and }<8 \text { per } \\
\text { month }\end{array}$ & 17.6 & 12.2 & $1.4(0.3-6.6)$ \\
\hline & $\geq 8$ per month & 66.2 & 66.3 & $0.9(0.3-3.2)$ \\
\hline \multirow[t]{2}{*}{ Veal } & Never & 87.1 & 81.8 & 1.0 \\
\hline & Ever & 12.9 & 17.5 & $0.5(0.2-1.5)$ \\
\hline \multirow[t]{3}{*}{ Liver } & Never & 38.6 & 41.6 & 1.0 \\
\hline & $\leq 1$ per year & 20.5 & 21.2 & $0.9(0.3-2.5)$ \\
\hline & $>1$ per year & 40.9 & 36.4 & $1.5(0.6-4.0)$ \\
\hline \multirow[t]{3}{*}{ Faggots } & Never & 64.7 & 68.7 & 1.0 \\
\hline & $\leq 1$ per year & 18.0 & 8.7 & $0.9(0.3-2.8)$ \\
\hline & $>1$ per year & 17.2 & 21.8 & $0.6(0.2-1.8)$ \\
\hline \multirow[t]{3}{*}{ Chicken } & $<1$ per week & 4.5 & 13.6 & 1.0 \\
\hline & 1 per week & 42.4 & 36.3 & $3.6(0.8-16.9)$ \\
\hline & $>1$ per week & 53.0 & 49.3 & $3.7(0.8-17.0)$ \\
\hline \multirow[t]{3}{*}{ Pork } & $<1$ per week & 22.0 & 16.2 & 1.0 \\
\hline & 1 per week & 37.1 & 27.2 & $1.3(0.4-4.1)$ \\
\hline & $>1$ per week & 40.9 & 55.9 & $0.8(0.3-2.3)$ \\
\hline
\end{tabular}

${ }^{a}$ Number of responses for cases varied between 123 and 132 .

${ }^{b}$ Proportions standardized to the birth cohort distribution of cases.

${ }^{\mathrm{c}}$ Number of responses for suspect cases varied between 28 and 33.

${ }^{\mathrm{d}}$ Adjusted for sex, north/south residence, and birth cohort.

${ }^{\mathrm{e}} \mathrm{MRM} /$ head meat: grouped measure that includes those items thought likely to contain MRM and/or head meat, that is, burgers, meat pies, and sausage. ${ }^{12-15}$

vCJD = variant Creutzfeldt-Jakob disease; $\mathrm{OR}=$ odds ratio; $\mathrm{CI}=$ confidence interval; $\mathrm{MRM}=$ mechanically recovered meat.

specialists. Thus, we cannot exclude the possibility that some of the observed differences related to the manner in which the interviews were performed. The most likely place for the introduction of such bias was in relation to medical histories, with more detail and accuracy obtained by NCJDSU nurses compared with control subject interviewers. Differences in the respondent type between case and control subjects might introduce bias, because of differences in how well the respondent knew the case/control during the relevant time period. However, analyses restricted to only those respondents who knew the case/control for the whole period since 1980 did not alter the results importantly.

Although the response rate from case relatives was high (98\%), that from control subjects was 57\%, with $87 \%$ of their relatives being interviewed. Although this response rate represents an improvement over our attempts to recruit control subjects through general practices, ${ }^{19}$ it is still lower than usually achieved by NatCen, ${ }^{20,28}$ perhaps because of the need to interview relatives of control subjects. A low response rate can introduce selection bias because it is possible that control subjects who agreed to take part were not representative of the general population in relation to some of the questions asked. That a higher proportion of control subjects than cases had been health-care workers (11.1 vs $5.4 \%$, see Table 4$)$ may reflect such selection bias.

Of necessity, information on possible risk factors was 
sought through relatives' recall of exposures and habits covering a period of 10 or more years before interview. This will have introduced errors into the classification of potential risk factors examined. If such misclassification was the same for cases and control subjects, it will have tended to obscure associations.

Perhaps most importantly, there has been extensive media coverage of the vCJD epidemic and much speculation on its causes. This might have affected responses, particularly from relatives of cases, who may have overreported, for example, the consumption of beef-related products compared with control relatives. To try to determine if such bias was present, we compared dietary data from vCJD cases with those from patients referred to NCJDSU with suspect vCJD, but who were subsequently diagnosed with another disorder. Responses from the relatives of this group of suspect cases $(\mathrm{n}=33)$ would be prone to the same recall bias as those from relatives of vCJD cases, because at the time of interview their relative thought the likely diagnosis was vCJD. The small number of suspect cases available for this analysis precludes firm conclusions, but the results (Table 8) suggest an attenuation of the dietary ORs when comparing cases with suspect cases, an observation compatible with recall bias being responsible for some of the associations in Table 2. The results in Table 8 were not materially altered by adjustment for the reported consumption of food items likely to contain MRM or head meat.

Overall, the results of this study do not provide any evidence for medical or occupational exposure as important mechanisms of acquiring the BSE agent. Our results are consistent with diet having been the major route of transmission of the vCJD agent, through contaminated beef and products containing MRM/head meat. The unexpected association with chicken consumption may be a chance finding. However, the scope for recall and selection bias must temper our interpretation of these observations.

Previously, the BSE agent was likely to have been widespread in food items that most people in the UK consumed, but with an uneven distribution over time and from one item of food to the next. The investigation of risks associated with diet a decade or more previously is fraught with potential biases. It is therefore difficult to obtain convincing evidence of a causal link between diet and vCJD through case-control studies. The probable transmission of $\mathrm{vCJD}$ by blood serves as a reminder of the possibility of human-to-human transmission of the vCJD agent and that risk factors may change as the vCJD epidemic evolves. ${ }^{8,9}$ It will be important to continue to monitor cases to investigate the routes by which they may have been infected and to verify reported medical histories from records.
This study, including control recruitment by the National Centre for Social Research, was supported by the UK Department of Health (121/7400; H.J.T.W., S.N., R.S.G.K., P.G.S., R.G.W.). This study received ethical approval from Lothian Multi-Research Ethics Committee (MREC/02/0/81).

We thank J. Mackenzie and N. Attwood for database management, A. Davies and C. Donaldson for data entry, and K. Sewell for administration. We thank those at the National Centre for Social Research for their input in control recruitment, especially $\mathrm{H}$. Cheshire and K. Sproston. We also thank the relatives of the CJD cases, the control subjects, and the relatives of control subjects for their participation in the study.

\section{References}

1. Will RG, Ironside JW, Zeidler M, et al. A new variant of Creutzfeldt-Jakob disease in the UK. Lancet 1996;347: 921-925.

2. Bruce ME, Will RG, Ironside JW, et al. Transmission to mice indicate that 'new variant' CJD is caused by the BSE agent. Nature 1997;389:498-501.

3. Collinge J, Sidle KCL, Meads J, et al. Molecular analysis of prion strain variation and the aetiology of 'new variant' CJD. Nature 1996;383:685-690.

4. Hill AF, Desbruslais M. The same prion strain causes vCJD and BSE. Nature 1997;389:448-450.

5. Scott MR, Will R, Ironside J, et al. Compelling transgenetic evidence for transmission of bovine spongiform encephalopathy prions to humans. Proc Natl Acad Sci U S A 1999;96: 15137-15142.

6. Anderson RM, Donnelly CA, Ferguson NM, et al. Transmission dynamics and epidemiology of BSE in British cattle. Nature 1996;382:779-788.

7. Ferguson NM, Donnelly CA, Woolhouse ME, Anderson RM. The epidemiology of BSE in cattle herds in Great Britain. II. Model construction and analysis of transmission dynamics. Philos Trans R Soc Lond B Biol Sci 1997;352:808-838.

8. Llewelyn CA, Hewitt PE, Knight RSG, et al. Possible transmission of variant Creutzfeldt-Jakob disease by blood transfusion. Lancet 2004;363:417-421.

9. Peden AH, Head MW, Ritchie DL, et al. Preclinical vCJD after blood transfusion in a PRNP codon 129 heterozygous patient. Lancet 2004;364:527-529.

10. Gore SM, Bingham S, Day NE. Age related dietary exposure to meat products from British dietary surveys of teenagers and adults in the 1980s and 1990s. BMJ 1997;315:404-405.

11. Philips Lord, Bridgeman J, Ferguson-Smith M. The BSE inquiry. Vol. 6. Human health, 1989-96. London: Stationary Office, 2000. Available at: http://www.bseinquiry.gov.uk/pdf/ index.htm. Accessed March 21, 2005.

12. Cooper JD, Bird SM. UK dietary exposure to BSE in beef mechanically recovered meat: by birth cohort and gender. J Cancer Epidemiol Prev 2002;7:59-70.

13. Det Norske Veritas Consulting. Sources of BSE Infectivity Project M03108 for the Food Standards Agency. London: DNV Consulting, 2002.

14. Cooper JD, Bird SM. UK bovine carcass meat consumed as burgers, sausages and other meat products: by birth cohort and gender. J Cancer Epidemiol Prev 2002;7:49-57.

15. Cooper JD, Bird SM. UK dietary exposure to BSE in head meat: by birth cohort and gender. J Cancer Epidemiol Prev 2002;7:71-83.

16. Will RG. Surveillance of prion diseases in humans. In: Baker HF, Ridley RM, eds. Methods in molecular medicine: prion diseases. Totowa, NJ: Humana Press, 1996:119-137. 
17. Will RG, Zeidler M, Stewart GE, et al. Diagnosis of new variant Creutzfeldt-Jakob disease. Ann Neurol 2000;47:575-582.

18. Department of Health. Monthly Creutzfeldt-Jakob disease figures. Available at: http:/www.dh.gov.uk/PolicyAndGuidance/ HealthAndSocialCareTopics/CJD/CJDGeneralInformation/fs/ en. Accessed February 24, 2005.

19. Ward HJT, Cousens SN, Smith-Bathgate B, et al. Obstacles to conducting epidemiological research in the UK general population: experiences from a case-control study of Creutzfeldt-Jakob disease. BMJ 2004;329:277-279.

20. National Centre for Social Research. Available at: http:// www.natcen.ac.uk. Accessed February 24, 2005.

21. Postcode Address File (PAF), Royal Mail UK. Available at: http://www.allies-computing.co.uk/datasupply.html. Accessed March 9, 2005.

22. Cousens S, Smith PG, Ward H, et al. Geographical distribution of variant Creutzfeldt-Jakob disease in Great Britain, 19942000. Lancet 2001;357:1002-1007.
23. Schlesselman JL. Case control studies. New York: Oxford University Press, 1982.

24. Huber PJ. The behaviour of maximum likelihood estimates under non-standard conditions. In: Proceedings of the Fifth Berkeley Symposium in Mathematical Statistics and Probability. Berkeley, CA: University of California Press, 1967:221-233.

25. Rogers WH. Regression standard errors in clustered samples. Stata Technical Bulletin 1993;13:19-23.

26. Noble M, Smith G, Penhale B, et al. Measuring multiple deprivation at the local level: the indices of deprivation. UK Department of Environment, Transport and the Regions, 2000.

27. Ward HJT, Everington D, Croes EA, et al. Sporadic Creutzfeldt-Jakob disease and surgery: a case-control study using community controls. Neurology 2002;59:543-548.

28. Sproston K, Primatesta P, eds. Health Survey for England 2003. Vol. 3. Methodology and documentation. London: Stationary Office, 2004. 